\title{
Visualisation Tools for Multi-Perspective, Cross-Sector, Long-Term Infrastructure Performance Evaluation
}

\author{
David Alderson', Stuart Barr', Martino Tran², Jim Hall², Alex Otto², Adrian Hickford ${ }^{3}$ and Edward Byers ${ }^{1}$ \\ ${ }^{1}$ School of Civil Engineering and Geosciences, Newcastle University, UK. \\ ${ }^{2}$ Environmental Change Institute, University of Oxford, UK. \\ ${ }^{3}$ Engineering and the Environment, University of Southampton, UK
}

\begin{abstract}
Across different infrastructure sectors there are systems that help to monitor the current and near-future operation and performance of a particular system. Whilst Supervisory Control and Data Acquisition (SCADA) systems are critical to maintaining acceptable levels of functionality, they do not provide insights over the longer timescales across which strategic investment decisions play out. To understand how individual or multiple, interdependent, infrastructure sectors perform over longer timescales, capacity/demand modelling is required. However, the outputs of such models are often a complex high-dimensionality result-set, and this complexity is further compounded when crosssector evaluation is required. To maximise utility of such models, tools are required that can process and present key outputs. In this paper we describe the development of prototype tools for infrastructure performance evaluation in relation to different strategic decisions and the complex outputs generated from capacity and demand models of five infrastructure sectors (energy, water, waste water, solid waste, transport) investigated within the UK Infrastructure Transitions Research Consortium (ITRC). By constructing tools that expose various dimensions of the model outputs, a user is able to take greater control over the knowledge discovery process.
\end{abstract}

Keywords: Visualisation, Infrastructure Performance, Cross-sector, Infrastructure Systems, Database

\section{INTRODUCTION}

The evolution of infrastructure systems has resulted in a complex system-of-systems that are highly connected and interdependent (Rosato, 2008) ${ }^{1}$. As a result it is a non-trivial task to model and interpret how such a system will evolve and subsequently perform in the future when facing changing demographic, economic, and climatic conditions. Traditionally each infrastructure sector (e.g. energy, transport, waste, water) monitors its own performance, often via targets prescribed by industry regulators such as OFCOM, OFGEM or OFWAT in the UK. For example, OFWAT has outlined water efficiency targets for each privatised UK water supplier, such as Northumbrian or Yorkshire Water, in an attempt to reduce water usage (OFWAT, 2007)2. In turn these targets are offered in an attempt to ensure water suppliers can adhere to the fixed prices negotiated every 5 years in the UK water sector (OFWAT, 2008) ${ }^{3}$. The perspectives gained from reviewing such performance indicators or targets are largely focussed on a

1 Rosato, V. S. (2008). A Complex System's View of Critical Infrastructures,. In D. Helbing, Managing Complexity: Insights, Concepts, Applications (pp. 241-260). Springer.

2 OFWAT. (2007). RD 15/07: Water efficiency targets. Retrieved 15 05, 2014, from OFWAT: http://www.ofwat.gov.uk/regulating/ltr_ rd1507_watefftargets

3 OFWAT. (2008). Setting the price limits for 2010-2015: Framework and Approach. Retrieved 10 03, 2014, from OFWAT: http://www. 
particular infrastructure sector, and do not allow for evaluation across different sectors or does not provide insight in to the interdependencies between sectors. Equally, such an approach does not allow an analysis of the longer term multi-decadal requirements for infrastructure planning to be addressed; an issue which has been recognised in the UK by the establishment of Infrastructure UK (IUK), (HM Treasury, Infrastructure UK, 2010)4, within HM Treasury, and through calls for an independent "National Infrastructure Commission" via Sir John Armitt's review of UK infrastructure planning (Armitt, 2013) $)^{5}$. As such, there is an urgent need for the development of new model paradigms and related analytical tools that enable the evaluation of potential impacts of decisions over the medium to long-term on infrastructure planning and investment (Council for Science and Technology, 2009, Recommendation 5).

Within the UK, the Infrastructure Transitions Research Consortium (ITRC) has developed a series of capacity and demand models (CDAM) that provide insight into the future performance of key infrastructure sectors utilising projections of future demographic and economic conditions (Zuo, Birkin, \& Malleson, 2013) ${ }^{7}$ as drivers, and adjustments to model parameters to reflect particular strategic decisions. As a result of executing each model, multi-dimensional data is produced. For decision makers, government agencies, managers of infrastructure assets, and the research community to understand the potential impacts and consequences of taking particular decisions a system to explore and visualise outcomes of different decisions and scenarios is essential (Lempert, 2002) ${ }^{8}$. In this paper we present a series of prototype visualisation tools that in combination will form the basis for an infrastructure performance visualisation and reporting framework. This will be used to evaluate performance from different perspectives with a view to understanding how different decision pathways impact infrastructure performance in the long-term. The tools developed draw on the result-sets of the sector-specific sub-strategies and strategy portfolios investigated in the ITRC capacity and demand models, which in turn employ a number of different economic and demographic scenarios; full details of the design concepts of the ITRC capacity and demand modelling can be found in Otto, et al. $2014^{9}$.

\section{INFRASTRUCTURE SECTOR STRATEGIES AND PORTFOLIOS}

Whilst decisions that are likely to impact infrastructure in the UK have historically occurred in a relatively ad-hoc manner (Council for Science and Technology, 2009; HM Treasury, Infrastructure UK, 2010) ${ }^{10,11}$, and have been derived from a multitude of complex interactions between infrastructure operators, regulators and government, there is an increasing body of evidence that a more coherent and coordinated approach is required (Tolone, 2009; HM Treasury, Infrastructure UK, 2013) ${ }^{12,13}$. Within ITRC a series of national infrastructure strategy portfolios were developed in order to package together options or interventions that employ different mixtures of regulation, technology choice and

ofwat.gov.uk/pricereview/pap_pos_pr09method080327.pdf

4 HM Treasury, Infrastructure UK. (2010). Infrastructure UK. Retrieved 10 03, 2014, from Infrastructure UK: https://www.gov.uK/ government/organisations/infrastructure-uk

5 Armitt, S. J. (2013). An independent review of long term infrastructure planning commissioned for Labour's Policy Review. Retrieved 10 03, 2014, from Your Britain: http://www.yourbritain.org.uk/uploads/editor/files/The_Armitt_Review_Final_Report.pdf

6 Council for Science and Technology. (2009). A National Infrastructure for the 21st Century. Retrieved 10 03, 2014, from Department for Business Innovation and Skills: http://www.bis.gov.uk/assets/bispartners/cst/docs/files/whats-new/09-1631-national-infrastructure

7 Zuo, C., Birkin, M., \& Malleson, N. (2013). Dynamic Microsimulation Modelling for National Infrastructure Demand in an Uncertain Future. Geocomputation 2013 Conference Proceedings. Wuhan, China

8 Lempert, R. J. (2002). A new decision sciences for complex systems. Proceedings of the National Academy of Sciences of the United States of America, 99 (3), pp. 7309-7313.

9,15,17 Otto, A., Hall, J. W., Hickford, A. J., Nicholls, R. J., Alderson, D., Barr, S., et al. (2014). A quantified system-of-systems modeling framework for robust national infrastructure planning. IEEE Systems, Accepted.

10 Council for Science and Technology. (2009). A National Infrastructure for the 21st Century. Retrieved 10 03, 2014 , from Department for Business Innovation and Skills: http://www.bis.gov.uk/assets/bispartners/cst/docs/files/whats-new/09-1631-national-infrastructure

11 HM Treasury, Infrastructure UK. (2010). National Infrastructure Plan. (2010, 25 10), National Infrastructure Plan, Retrieved 10 03, 2014, from National Infrastructure Plan: https://www.gov.uk/government/publications/national-infrastructure-plan-october-2010

12 Tolone, W. J. (2009). Interactive visualisations for critcal infrastructure analysis. International Journal of Critical Infrastructure Protection, 2 (3), 124-134

13 HM Treasury, Infrastructure UK. (2013). National Infrastructure Plan. (2013, 16 04). National Infrastructure Plan. Retrieved 10 03, 2014, from National Infrastructure Plan: https://www.gov.uk/government/collections/national-infrastructure-plan 
investments (Hall et al., 2012; Otto, et al., 2014)14. The different mixtures used are represented via a series of sectorspecific sub-strategies, with either the capacity or demand within a sector influenced by adjustments to the three aforementioned components in relation to the input capacity-demand model (CDAM) parameters (Tran, et al., 2014) ${ }^{16}$. The process of sub-strategy definition and how they are combined to build a particular strategy portfolio is considered in greater detail in Otto, et al. 2014 ${ }^{17}$. Table 1 shows in general terms how the 4 strategy portfolios investigated were constructed with respect to the sector specific sub-strategies (Tran, et al., 2014) ${ }^{18}$. Two initial performance metrics were defined to evaluate and compare the performance of each strategy portfolio. These were, an assessment of environmental performance measured in terms of Carbon Dioxide $\left(\mathrm{CO}_{2}\right)$ emissions from the key sectors, and a calculation of investment. The performance and comparison of the different strategy portfolios was undertaken for 2010 , 2030 and 2050. Subsequent visualisation tools for both individual sectors and cross-sector comparison were developed using this initial ITRC CDAM set of strategy portfolios and related performance metrics.

Table 1 - Table depicting the combinations of sector-specific strategies used to generate the cross-sector strategy portfolios.

\begin{tabular}{|c|c|c|c|c|c|}
\hline Sub-strategies $\downarrow$ & $\begin{array}{l}\text { Strategy } \\
\text { portfolios } \rightarrow\end{array}$ & $\begin{array}{l}\text { Minimum } \\
\text { Intervention } \\
\text { Portfolio [P-MI] }\end{array}$ & $\begin{array}{l}\text { Long-term Capacity } \\
\text { Expansion Portfolio } \\
\text { [P-CE] }\end{array}$ & $\begin{array}{l}\text { Increasing System } \\
\text { Efficiency [P-SE] }\end{array}$ & $\begin{array}{l}\text { New Services and } \\
\text { Planning [P-NS] }\end{array}$ \\
\hline Energy ${ }^{\ddagger}$ & & $\begin{array}{l}\text { ENO - Minimal } \\
\text { policy intervention }\end{array}$ & $\begin{array}{l}\text { EN2 - Electrification } \\
\text { of heat and } \\
\text { transport }\end{array}$ & $\begin{array}{l}\text { EN2 - } \\
\text { Electrification } \\
\text { of heat and } \\
\text { transport }^{* *}\end{array}$ & $\begin{array}{l}\text { EN2 - } \\
\text { Electrification } \\
\text { of heat and } \\
\text { transport }^{* *}\end{array}$ \\
\hline Transport & & $\begin{array}{l}\text { TRO - Decline } \\
\text { and decay }\end{array}$ & $\begin{array}{l}\text { TR1 - Predict and } \\
\text { provide }\end{array}$ & $\begin{array}{l}\text { TR3 - Adapting } \\
\text { the fleet }\end{array}$ & $\begin{array}{l}\text { TR6 - Smarter } \\
\text { choices }\end{array}$ \\
\hline Solid Waste & & $\begin{array}{l}\text { WEO - Business } \\
\text { as usual }\end{array}$ & WE1 - High tech & WE3 - Deep green & $\begin{array}{l}\text { WE3 - Deep } \\
\text { green }\end{array}$ \\
\hline Waste Water & & $\begin{array}{l}\text { WWO^ - Current } \\
\text { trends }\end{array}$ & $\begin{array}{l}\text { WWO+ - Current } \\
\text { trends }\end{array}$ & $\begin{array}{l}\text { WWO }{ }^{\Delta} \text { - Current } \\
\text { trends }\end{array}$ & $\begin{array}{l}\text { WWO }{ }^{\Delta} \text { - Current } \\
\text { trends }\end{array}$ \\
\hline Water & & $\begin{array}{l}\text { WSO^ - Current } \\
\text { trends }\end{array}$ & $\begin{array}{l}\text { WSO+ - Current } \\
\text { trends }\end{array}$ & $\begin{array}{l}\text { WSOA - Current } \\
\text { trends }\end{array}$ & $\begin{array}{l}\text { WSOA - Current } \\
\text { trends }\end{array}$ \\
\hline
\end{tabular}

‡Energy model comprised of two separate models, one demandside, and one supply-side

\section{${ }^{\wedge}$ Central population scenario}

*with High Nuclear

\section{+High population scenario}

${ }^{4}$ Low population scenario

\section{**with High Carbon Capture and Storage}

\section{${ }^{* * *}$ with High Offshore}

\section{VISUALISING AND COMPARING CROSS-SECTOR PERFORMANCE}

To facilitate the cross-sector exploration of the outputs from executing all the models for the defined sub-strategies (Table 1 rows) that combine to form the strategy portfolios (Table 1 columns), an initial prototype visualisation interface was developed using open-source server-side database technologies, PostgreSQL and PostG/S, via the use of the Python-powered Django web framework coupled with custom client-side JavaScript scripts and Highcharts library (Figure 1). A user is able to control which strategy portfolios to display via checkboxes, resulting in a POST request to the server-side ITRC database (Barr et al., 2013) to retrieve the relevant data. In the tool, a user can obtain more information on a strategy portfolio by placing the mouse cursor over either the bars representing cumulative investments or the points representing emissions. This invokes a script that dynamically-generates a data

14, Hall, J. W., Henriques, J. J., Hickford, A. J., \& Nicholls, R. J. (2012). A Fast Track Analysis of strategies for infrastructure provision in Great Britain: Executive Summary. Environmental Change Institute. University of Oxford. 
label or tooltip that reports the relative contributions from each sector for the selected year (Figure 1). Furthermore, a user is able to decide which sectors they wish to investigate by clicking the appropriate item from the chart legend found beneath the chart. A consistent colour scheme for each sector is employed to more easily determine emissions and investments attributable to each sector.

By combining the display of both metrics within the visualisation canvas it allows a user to visually and quantitatively explore the differences between different strategy portfolios both in absolute terms and also in terms of individual sectors within each of the strategy portfolios. This ability allows a user to understand the potential trade-offs involved within and between strategy portfolios in terms of environmental performance via carbon emissions and investment. For example, Figure 1 shows that the Long-term Capacity Expansion (P-CE) strategy portfolio offers high levels of investment, particularly within the transport sector (red) as a result of widespread expansions to the road network, coupled with high levels of carbon emissions, while the Increasing System Efficiency (P-SE) strategy portfolio offers reduced levels of investment alongside significantly lower carbon emissions over the modelled time horizon (Tran, et al., 2014). However, in its current form the visualisation tool via the available metrics cannot give an indication as to the trade-offs between available capacity as a result of differences in investment, an issue that will be addressed in the further development of cross-sector performance metrics.

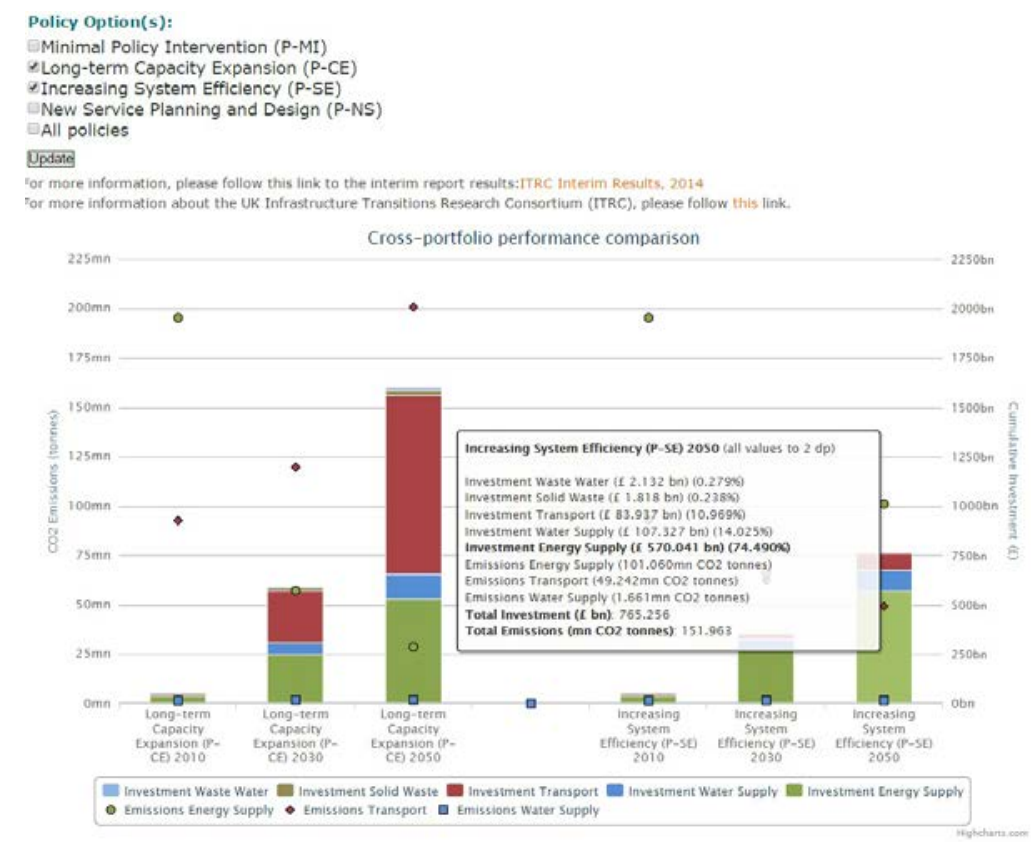

Figure 1 - Reporting cumulative investment and $\mathrm{CO} 2$ emissions for all evaluated strategy portfolios.

\section{SINGLE-SECTOR PERFORMANCE COMPARISON}

To further expose the modelling outputs of the ITRC CDAM models and to begin to explore ways that individual sectors may be analysed, interrogated, and presented with respect to the strategy portfolios generated, a number of web-based prototype visualisation user interfaces have been developed. Each of these has been designed to extend the static figures that were initially generated for the written report of the CDAM work (Tran, et al., 2014). Figure 2 illustrates an example interface showing the changes in the electricity power transmission network, as modelled within the energy supply CDAM, over time for the different energy supply sub-strategies. A user is able to choose which sub-strategies to display via the checkboxes at the top of the screen, and can choose which of the 5 available 10-year time steps to display via the legend next to each chart. A user is able to retrieve data values from the charts by hovering over the bar of interest, and is also able to select particular busbars links to highlight (red outline) by clicking on the map and holding the Shft key (Figure 2). 


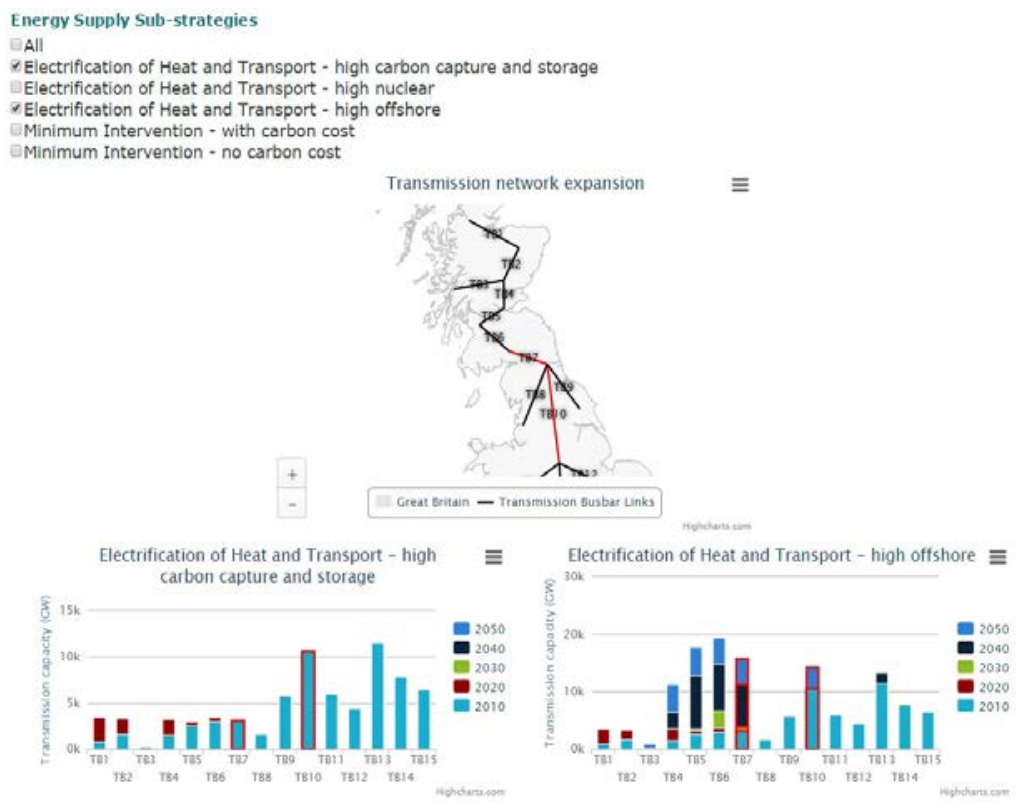

Figure 2 - Visualising the energy supply power transmission network expansion for different energy supply sub-strategies over time

\section{VISUALISING CROSS-SECTOR INTERDEPENDENCE: COOLING WATER USAGE FROM ELECTRICITY GENERATION}

As part of the ITRC CDAM modelling a number of interdependencies between infrastructure sectors were explored by taking the outputs from one particular sector model and using it as inputs within another model in order to specifically investigate the relationship between sectors (Tran, et al., 2014). For example, in order to understand potential changes in water usage as a result of employing alternative mixes of energy generation technologies, a separate model for water usage from energy generation was developed (Byers, Hall, \& Amezega, 2014) that requires energy generation (GWh) and capacity (MW) outputs from the energy supply CDAM disaggregated by generation technology types, year, season, and busbar link. Results from the water usage model were stored in the ITRC database (Barr, et al., 2013) and a suite of open source JavaScript libraries were used to develop a visualisation tool that allows users to explore dynamically for different energy sub-strategies the potential impact on water usage from fresh, sea and tidal sources. The tool developed makes use of a Sankey diagram (Bostock, 2012) which expresses visually the relative quantities of different water types used from different energy generation technologies, in different regions in the UK, for different time periods (Figure 3). 




Figure 3 - Sankey diagram visualisation showing quantity of water usage as a result of different energy generation technology mixes influenced by each energy supply sub-strategy (indicative values).

To offer an alternative approach to visualise the same data, a further interface was developed (Figure 4). This approach exports the contents of the database tables powering the Sankey diagram shown in Figure 3 to a separate Geographic JavaScript Object Notation (GeoJSON; Butler, et al,. 2008) ${ }^{19}$ file which is subsequently accessed via a request to the server. Custom JavaScript is used, along with the Highcharts and Highmaps libraries to build the interface. A user is able to choose what data to display by Ctrl-selecting multiple locations on the map to retrieve different combinations of charts beneath. The charts show the quantity of water abstraction and consumption for the base year 2010, as well as for all energy supply sub-strategies in 2050. The sub-strategies are reflected in the categories across the $\mathrm{x}$-axis. Inspection of Figure 4 shows a comparison of the abstraction and consumption water levels for Yorkshire and the Humber, and the East Midlands regions of the UK. By using this tool, and by allowing a user to control what regions of interest to display it is possible to determine where alternative energy generation mixes (as defined by the different energy supply strategies evaluated) are going to have the greatest impact on fresh water usage. In this case, it is apparent that levels of freshwater abstraction and consumption for Yorkshire and the Humber are much greater in 2050 under the Electrification of Heat and Transport (with high carbon capture and storage) strategy, compared to other strategies for that region, and compared to the East Midlands region across all strategies. An important aspect of this tool is that a user is able to decide which geographic regions to compare at any one time, and is able to retrieve data values for these directly, without having to refer to the original data tables generated from the CDAM modelling.

19 Butler, H., Daly, M., Doyle, A., Gillies, S., Schaub, T., \& Schmidt, C. (2008). The GeoJSON Format Specification. Retrieved 0502,2014, from geoJSON.org: http://geojson.org/ 




Figure 4 - Visualising water usage from energy generation under different energy supply sub-strategies, over time. This example is for freshwater abstraction and consumption only.

\section{FUTURE WORK}

The ITRC project has initiated an ambitious programme of capacity and demand modelling of infrastructure sectors and their interdependencies. To date our ability to interrogate, analyse, and present the outputs of such models has been limited. In order to maximise the utility of modelling dedicated visualisation systems are required that can directly query the model outputs via the ITRC database to extract, synthesise and present relevant sub-sets of results for decision making purposes. The tools presented in this work are an initial start on developing such a software framework. In future, however, a much broader and detailed set of analytical middleware is required that acts as a broker between the model outputs in the ITRC database and the web-based visualisation interfaces. The model outputs will be generated in a coordinated fashion via the use of the integrated system-of-systems modelling framework currently in development that will enable all infrastructure sector models to be executed together and the results subsequently explored. This will enable more strategies representing particular decisions on infrastructure for a wider range of demographic and economic scenarios to be evaluated. A user will be able to view different cross-sector or sector-specific visualisations of the modelled outputs and subsequently export the images and data for publication in reports, or for further investigation. Furthermore, additional performance metrics, alongside investment and $\mathrm{CO}_{2}$ emissions, related to capacity utilisation and total service delivery will be developed and included within the extended visualisation and reporting framework. 


\section{CONCLUSION}

Through the use of computer models representing five key infrastructure sectors within the UK (energy, water, waste water, solid waste, transport) evaluations of the potential impacts of different decision pathways taken regarding infrastructure have been performed; the interim results of which are available in Tran, et al., 201420. Due to the highly complex systems being modelled, the resultant data is also highly complex with multiple dimensions. Through the use of database technologies and scripting and JavaScript libraries, ITRC has produced a set of prototype visualisation tools that will enable users to review and explore the outputs from these computer models. Through the use of these technologies, directly coupled to model output data, the currency of each visualisation can be maintained as new data becomes available, giving prospective users more opportunity to discover new insights and interact with new outputs (Fox \& Hendler, 2011) ${ }^{21}$. For example, as new strategy portfolios of strategic decisions are formulated and tested, the results can be made available via web-based interfaces, such as those presented in this paper. The prototypes developed will be extended as part of ITRC CDAM modelling that will develop an ITRC system-of-systems modelling framework.

The authors would like to acknowledge funding from the Engineering and Physical Sciences Research Council (EPSRC) grant EP/I01344X/1 to the Infrastructure Transitions Research Consortium (ITRC), and the respective authors' host institutions of Newcastle University, University of Oxford and Southampton University.

20 Tran, M., Hall, J. W., Hickford, A. J., Nicholls, R. J., Alderson, D., Barr, S. L., et al. (2014). National infrastructure assessment: Analysis of options for infrastructure provision in Great Britain, Interim results. Environmental Change Institute. University of Oxford.

21 Fox, P., \& Hendler, J. (2011). Changing the equation on scientific data visualization. Science , 705-708. 